\title{
Filología e historia en la Edad Media castellana
}

\author{
Francisco Abad Nebot \\ UNED
}

\begin{abstract}
RESUMEN ABSTRACT
Este articulo trata de varios aspectos históricos y filológicos de la Edad Media castellana, como la distribución territorial, los nombres de lugar, la periodización de la historia de la lengua, etc.

This article explores a number of historical and philological aspects concerned with Castillian Middle Ages: territorial distribution, place names, the division of the language in various periods, et cetera.

\section{PALABRAS CLAVE}

Fernand Braudel, periodización de la Historia de la lengua, Alfonso $X$, Castilla la

Nueva

KEY WORDS

Fernand Braudel, division of the language in various periods, Alfonso X, Castilla la Nueva
\end{abstract}

\section{INTRODUCCIÓN}

Para entender bien alguna referencia y reflexión cronológica que vamos a hacer, debemos situarnos primero ante las primeras épocas en la historia del idioma patrimonial que cabe delimitar. En efecto creemos que debe seguirse la idea de Menéndez Pidal acerca de una periodización corta de la diacronia de la lengua, aunque no debe desconocerse tampoco $-\mathrm{y}$ ambos hechos son compatibles, por supuesto- la larga duración que presentan las respectivas difusiones de algunos cambios fonéticos, la larga vigencia de algunos rasgos gramaticales, la vigencia asimismo secular del léxico, etc. En la historia coexisten procesos de larga duración con duraciones cronológicas medias, ..., y aún antes de las referencias aludidas a la periodización general del idioma vamos a recordar -pues resulta pertinente- las distinciones cronológicas que en la densidad del tiempo proponía de- 
limitar el historiador Fernand Braudel, así como sus observaciones sobre la dimensión social de la vida histórica, si bien todo ello lo relacionaremos con la filología.

\section{"LAS RESPONSABILIDADES DE LA HISTORIA"}

En la "Lección inaugural" en el Collège de France (1950), dedicada a subrayar algunas de las responsabilidades de la Historia en cuanto saber, enfatizaba Braudel sobre el hecho de que la realidad de lo social es la realidad fundamental del hombre "; no existimos sino en colectividades de mayor o menor círculo, y en ellas nos definimos y somos en realidad.

El pasado se halla constituido así por sociedades, por una delimitación de agrupaciones, y además considerar lo social en el lenguaje es hacerse cargo de la partición de su vigencia según regiones, diastratias, hablas técnicas, etc., pues el idioma se diversifica según su escindida implantación social: todos estos son hechos de la realidad empírica. La historia idiomática se diversifica múltiplemente según épocas, regiones, estilos del hablar ordinario y estilos literarios, jergas, diacronías, ..., y de esta forma lo estableció Menéndez Pidal tanto en su obra magna Origenes del español como en la Historia de la lengua que hizo hasta 1713 y que conocemos fragmentariamente y va a ser publicada se dice que pronto.

"Jamás se da en la realidad viva —manifestaba entonces por igual Braudelun individuo encerrado en sí mismo; todas las aventuras individuales se basan en una realidad más compleja: una realidad «entrecruzada», como dice la sociología». Ciertamente la realidad del tejido de la vida resulta del entrecruzamiento de relaciones y situaciones que se definen por tales relaciones; en lo idiomático el hablante se define siempre por su pertenencia social (estamento o clase y grupo), cultural (grado de instrucción), conciencia de ese lugar social (relaciones asimétricas de respeto al usar las fórmulas de tratamiento, al organizar el discurso), etc.

Braudel enunciaba en fin la proclama de que "hay que abordar, en si mismas y para si mismas, las realidades sociales"; la adecuación empirica y la adecuación explicativa exigen ajustarse a las dimensiones del pasado, y estamos viendo la dimensión social; de ahí que haya que abordar las dimensiones sociales de la historia. Entre nosotros José Antonio Maravall evolucionó en su trayectoria historiográfica hasta llegar al postulado de una historia social del pensamiento, o lo que prácticamente vino a ser lo mismo, una historia de las mentalidades sociales, y así la ensayó en sus estudios sobre Gracián, sobre la comedia de Lope de Vega, o - en el que algunos tienen por uno de sus mejores, si no el mejor libro- sobre la literatura picaresca; asimismo en sus escritos galdosianos o referidos a Ramón J.

Estas primeras alusiones y citas textuales serán de F. BRAUDEL, La Historia y las ciencias sociales, trad. cast., Madrid, Alianza, 1968, pp. 19-46. Rehacemos en los presentes párrafos iniciales que siguen una exposición anterior 
Sender, José María Jover ha hecho otras tantas calas en mentalidades referibles socialmente al tiempo del Ochocientos o de la segunda República..

A su vez la incidencia en lo idiomático de la ordenación social (la estratificación del hablar), los ideales de la estilística de la lengua en cuanto se hallan distribuidos según agrupaciones sociales, los cambios y las situaciones lingüísticos que se derivan de todo ello, no debe dejar de atenderlos la Historia de la lengua, y en una u otra medida la mejor Historia de la lengua lo hace.

Nuestro autor enunciaba en fin en su "Lección Inaugural»:

La dificultad no radica en conciliar, en el plano de los principios, la necesidad de la historia individual y de la historia social; la dificultad reside en ser capaz de tener sensibilidad para ambas al mismo tiempo y en conseguir apasionarse por una de ellas sin por ello olvidar a la otra.

La estilistica de la lengua es en realidad una estilistica social, compartida por la comunidad hablante o por partes de ella, y estilos sociales son algunos registros del hablar, pues se hallan vinculados a grupos especificos; la historia individual a su vez resulta necesaria, e. gr., la estilística de Juan Ruiz, la del canciller Ayala, la de Santillana, la de Jorge Manrique, la de Fernando de Rojas, etc. Lo individual y lo social entran en las situaciones idiomáticas, y la diacronía ha de hacerse cargo de ello: difusión de los cambios idiomáticos según geografías y diastratías, dialectos de grupo, estilos artísticos personales, etc.

En la lengua hay innovaciones y usos individuales en el caso de grandes escritores, y asimismo diferentes gustos lingüisticos - tal como los denominaba Menéndez Pidal - con una u otra vigencia social, estructuras idiomáticas condicionadas por lo social, etc.: la diacronia, según decimos, deberá recogerlo.

\section{LARGA DURACIÓN Y DURACIONES MEDIAS}

Otra realidad que importa es la de los tiempos internos del pasado: así de unos años más tarde es otro (y célebre) escrito braudeliano, el que trataba de “La larga duración", el cual empezaba por distinguir desde luego la existencia de un "tiempo corto": "existe - manifestaba - un tiempo corto de todas las formas de la vida"; se trata del tiempo corto de los acontecimientos, de los eventos, de los hechos particulares en sí. La secuencia más superficial de lo histórico es justamente esta de los episodios y acaeceres.

En la diacronía lingüística la verdad es que tal tiempo corto apenas si lo encontramos, pues el idioma no cambia de un dia para otro ni de un año para otro: el idioma tiene gran consistencia tradicional, y así es muy lento en sus innovaciones; hay en todo caso innovaciones léxicas o fraseológicas que alcanzan una duración más o menos efímera, limitadas a grupos sociales muchas veces, que hoy - con la radio y sobre todo la televisión- toman vigencia casi instantáneamente y se olvi- 
dan asimismo pronto (por ej. el "pecador» o el "¿te das cuen?", de un humorista malagueño). El «tiempo corto» no es un atributo de la naturaleza del lenguaje, antes al contrario.

Hay en lo histórico en general —señalaba además nuestro autor- "oscilaciones cíclicas»: en la trayectoria del lenguaje podemos considerar por nuestra parte que esos ciclos responden a épocas de duración media, por ej., la época de Juan Ruiz y del principe don Juan Manuel en la historia del castellano, o la de Juan II, etc. Existe así "un recitativo [...] que para estudiar al pasado lo divide en amplias secciones: decenas, veintenas o cincuentenas de años". Traído a lo idiomático, nosotros creemos que cada etapa o época discernible analíticamente en el pasado de la lengua debe ser de unos treinta años o un tercio de siglo: esta es la medida que poseen los asuntos humanos en general, la de unos treinta años, según mantienen historiadores prestigiosos. La vida — hemos oído decir coloquial y simplificadamente a autor de relieve- cambia cada treinta años.

Según hemos recordado antes y asimismo alguna otra vez, fue Menéndez Pidal quien postuló una periodización más corta que la del siglo; lo hizo al tratar del lenguaje castellano del Quinientos, y su párrafo debe quedar estampado en tanto testimonio documental y programa personal que creemos debe ser adoptado por su mayor adecuación:

Para articular razonablemente cualquier exposición histórica, el primer cuidado [...] debe ser el de quebrar ese mecánico y descomunal molde [de la historia dividida en siglos, ] para ver cómo la materia en él encerrada se nos presenta dividida en otras porciones cuajadas por sí mismas [...] Me propongo indicar someramente una periodización más corta que el siglo, una estimación más precisa del factor temporal, que nos pueda encaminar hacia individualidades históricas más reales ${ }^{2}$.

De lo que se trata en efecto es de deslindar y someter a análisis las individualidades históricas reales, es decir, lo empírico real del pasado, lo que por su propia consistencia exige adecuación empírica del que estudia tal consistencia, y para ello ha de quebrarse la periodización "descomunal" sólo por centurias. En la diacronía de la lengua una de las duraciones que posee realidad en sí es la que indicamos de hacia un tercio de siglo, y es lo que don Ramón sugería con la concreta periodización que propuso: $1492-1525 ; 1525-1555 ; 1555-1585$; etc. Nosotros vamos a ver luego la posible periodización que cabe distinguir en la lengua castellana medieval ${ }^{3}$.

Pero debemos volver en este momento - en nuestro hilo argumental- a Fernand Braudel, quien asimismo delimitaba una historia «de amplitud secular»: se

2 Menendez Pidal, Ramón: «El lenguaje del siglo xVI», Cruz y Raya, 6 (1933), pp. 7-63: pp. 9-10.

${ }^{3}$ Es de lamentar técnicamente - creemos al menos nosotros- que lo mismo la periodización que la cronologia interna de los procesos idiomáticos aparezcan tan diluidas en alguna extensa exposición de la materia. 
trata (apostillaba) «de la historia de larga, incluso de muy larga duración». Señalaba además el historiador francés cómo "la palabra estructura [...] domina los problemas de larga duración", pero ciertamente cabe decir asimismo que las duraciones medias constituyen por igual "estructuras" de lo histórico: la Edad Media castellana resulta una larga duración, pero hay otras duraciones menores que asimismo suponen estructuras; en el medievo peninsular se distinguen a veces los siglos VIII a X; XI a XIII; y XIV-XV. Estructuras históricas son asimismo el Renacimiento, la llustración, ...

Todo lo que en la diacronía lingüística no resulte episódico y meramente coyuntural -por otra parte-, responde a estructuras de lo histórico-idiomático y es estructural, y la evolución lingüística puede decirse entonces que resulta inducida (en parte a veces, pues asimismo interactúa lo histórico-social) por lo estructural.

Dice muy bien Braudel que «la historia es la suma de todas las historias posibles", la de las estructuras largas o menos largas más los acontecimientos; igual ocurre con la historia lingüistica: han de tenerse presentes a la vez el tiempo corto - el de una innovación léxica efímera-, el tiempo de la media duración que proponemos se considere en el alrededor de unos treinta años, y el tiempo de las largas duraciones, de los cambios cuya implantación resulta multisecular («el único error - dice a la vez nuestro autor- [...] radicaría en escoger una de estas historias a expensas de las demás»).

La delimitación braudeliana dentro del mero tiempo físico externo, de tiempos específicos o modulaciones cronológicas, nos parece enteramente pertinente en la historia lingüística; con Braudel — parafraseanso su enunciado-, hay que decir asimismo que la Historia de la lengua es la suma de todas sus historias posibles, la suma de sus medias y largas duraciones, e incluso la que registre las innovaciones efímeras: así el Diccionario histórico de la Academia se propone dar cuanta de todos los usos de los que quede testimonio documental, aunque fuera sólo uno.

\section{LA LARGA DURACIÓN: LA DIFUSIÓN DE LAS LEYES FONÉTICAS}

Para Braudel hemos visto que hay un tiempo histórico de amplitud secular, y este tiempo interno secular y de verdadera larga duración en que también tiene una de sus consistencias la historia idiomática, quedó atendido asimismo por el maestro Menéndez Pidal. Entre los varios textos suyos que podriamos tener presentes ahora nos vamos a limitar en tanto ilustración a uno solo.

Nuestro autor tiene en cuenta que al estar completamente difundido el idioma por todos los grupos sociales, las innovaciones se implantan muy despacio, lenta o tardigradamente; Pidal manifestaba por tanto: «Un cambio fonético no suele ser nunca obra exclusiva de las tres o cuatro generaciones en que de un modo arbitrario se considera dividida la población convivente, sino que es producto de una idea o un gusto tradicional que persiste a través de muchas generaciones de ha- 
blantes. La duración del cambio fonético suele ser extraordinariamente larga, multisecular ${ }^{4}$.

La lengua es en efecto continuidad tradicional, aunque continuidad rota por innovaciones; esa continuidad o casi inmovilidad diacrónica se sustenta en que en efecto el acto infinitamente repetido del hablar se acomoda a patrones tradicionales y establecidos, patrones que no pueden violentarse y llegar a sustituirse sino de manera muy difícil, ya que hay que vencer el consenso común anteriormente establecido. El hablar se halla difundido por toda la comunidad, y es muy lento hacer cambiar en sus usos a la comunidad entera, ya que si cada idiolecto resultase más o menos aleatorio y caprichoso, se habría perdido la inteligibilidad mutua.

En realidad no es la duración del cambio, sino su difusión o implantación lo que se prolonga por siglos en ocasiones, pero en todo caso estamos ante largas duraciones; don Ramón lo ejemplifica para los tiempos medievales con ejemplos como este:

La evolución -iello > -illo se documenta ya en el siglo $x$, pero continúa en estado latente hasta el siglo $\mathrm{xl}$; aparece tolerada de mejor o pero gana en los siglos x\|l a $\mathrm{XIV}$, con notorias reacciones en las regiones más arcaizantes en favor de -iello, hasta que en los siglos XIV y XV el neologismo -illo se hace preponderante ${ }^{5}$

Vemos que un neologismo se va abriendo paso según épocas y regiones, hasta hacerse vigente; en los primeros tiempos vive en parte en estado latente, esto es, no registrado por escrito, no documentado, y con implantación nada más que oral $^{6}$.

La duración multisecular establecida por don Ramón para el cambio fonético, los reajustes gramaticales asimismo pluriseculares que podemos analizar nosotros, constituyen casos de lo que Braudel denominaba "larga duración». En literatura hay larga duración cuando se repiten unos mismos «motivos» o topoi retóricos, cuando vive por varios siglos el romancero, etc.; en la lengua hay asimismo largas duraciones, y también duraciones medias de unos treinta años, o por igual innovaciones efímeras. La historia filológica se encuentra en la historia de todas sus duraciones sumadas.

\section{CUESTIONES DE PERIODIZACIÓN}

La Crestomatía del español medieval hecha en tanto obra de escuela por el mismo Menéndez Pidal y sus discípulos, lleva ya a cabo una periodización corta

\footnotetext{
Menendez Pidal, Ramón: Origenes del español, Madrid, Espasa-Calpe, 198610, p. 533.

5 Ibid., p. 534.

" "Formas innovadoras y formas conservadoras suelen convivir por siglos", recuerda Concepción COMPANY, "Reanálisis en cadena y gramaticalización. Dativos problemáticos en la historia del español». Verba, 29, 2002, pp. 31-69
} 
del idioma de los siglos medios, aunque distingue épocas un tanto dispares en su misma duración; creemos más adecuado proponer otra no siempre coincidente, ya que la unidad natural de lo histórico es la de unos treinta años o un tercio de siglo, y debemos respetar este dato empírico general de la consistencia de todo lo histórico, según queda apuntado; para no hacer más complicadas las cosas, nos adaptamos no obstante todo lo posible a la Crestomatía. Atendiendo pues a épocas que más o menos se diferencian (siempre que puede analizarse así) cada tercio de siglo, y empezando - antes del castellano alfonsi o estándar - por el anterior período de un idioma casi siempre meramente oral "vernáculo", que no se emplea todavía para todos los usos (los orales y los escritos), proponemos esta periodización interna de la lengua medieval:

- Época de origenes próximos del español: desde poco antes de 900 hasta h. 1140

- Época de h. 1140-1207: Poema del Cid, Fuero de Avilés, Fuero de Madrid, etc.

- 1205-1250: Época de La Fazienda de Uitra Mary de Berceo.

-- 1250-1284: Época de Alfonso X.

- 1284-1320: Época de la herencia alfonsí.

- 1320-1351: Época de Alfonso XI7.

- 1351-1385: Época de don Sem Tob y de comienzos de la poesía de cancionero.

- 1385-1416: Época del canciller Ayala y de orígenes del retoricismo ${ }^{8}$.

- 1416-1454: Época de Juan II.

- 1454-1492: Época de Jorge Manrique y de Juan de Lucena.

Proponemos en efecto la presente periodización interna del idioma de la Edad Media, por creerla más respetuosa con los hechos particulares que la algo distinta que aparece en la Crestomatía...; las fechas se hallan siempre motivadas inmanentemente por datos de relieve bien lingüísticos o bien lingüístico-literarios.

En todo caso no ha de olvidarse nunca que la diacronía idiomática es un continuo en el que existen discontinuidades, y que los periodos que sugerimos indican tales discontinuidades sobre un fondo de hechos tradicionales y continuos.

En 1320 comienza la actividad como escritor de don Juan Manuel, según señala la crítica.

* LAPESA EScribió en un momento: "En cuanto a estilo, lenguaje y afán por crear una poesia sabia, [cupo a Imperiał] ser el más destacado iniciador del movimiento que en nuestra literatura es paralelo al de los rhétoriqueurs franceses"; a su vez "el florecimiento de. Imperial como poeta parece corresponder a [...] los comienzos del siglo xv hasta 1407" ( Notas sobre Micer Francisco Imperial», en De la Edad Media a nuestros dias, Madrid, Gredos, 1967, pp. 76-94). Vid. asimismo su articulo "Un ejemplo de prosa retórica a fines del siglo xiv: los Soliloquios de Fray Pedro Fernández Pecha", incorporado a Poetas y prosistas de ayer y de hoy, Madrid, Gredos, 1977, pp. 9 y ss, más la bibliografía de la nota 17 a pie de página; en fin y para el canciller Ayala los dos primeros capitulos que inserta en De Ayala a Ayala, Madrid, Istmo, 1988. Ayala es de los autores que quedan aún por estudiar idiomáticamente. 
Hasta 1385 se conoce aceptablemente la lengua de textos literarios, Fueros, etc., y asimismo se conoce la lengua de tiempos de Juan II; salvo el propio canciller Ayala y algunas otras cosas, el idioma medieval resulta ciertamente conocido, aunque desde luego hay asuntos y problemas que quedan aún por analizar.

(Desde el Renacimiento hasta nuestros días transcurren de acuerdo con el análisis temporal que proponemos subperiodos o épocas en la historia de la lengua, los dos primeros de los cuales son:

- 1492-1526: Época de Nebrija y de Torres Naharro.

- 1519-1554: Época de Garcilaso y del erasmismo).

Tenemos pues una partición del castellano medieval que incluye un periodo inicial primitivo de origenes, y luego épocas ya literarias que van cuajando sucesivamente. Lo medieval se va diluyendo en la etapa 1519/1554: la prosa se estima que ya no es prosa medieval desde los textos de hacia 1519; el verso experimenta una revolución con Boscán y Garcilaso tras 1526; la fonética toledana decía Menéndez Pidal que hace crisis tras $1535 ;. .$. Pero para tener en cuenta la situación de la distribución del idioma, hay que considerar ya la época 1492-1526, en que la lengua castellana se difunde en Europa y asimismo en América.

Con el tiempo de Carlos $V$ se produce una discontinuidad en la historia general que advirtió nuestro admirado compañero a quien llevamos en la memoria José Luis Martín Rodríguez:

Fernando e Isabel -enseñaba- serán Reyes de Castilla en 1474 y de Aragón en 1479 , pero cada uno es rey en su reino y sólo el heredero podrá unificar ambos reinos y completar la unidad de Hispania [...] La unidad de las tierras peninsulares [...] se realiza a partir del reinado de Carlos $V$, primer rey de pleno derecho de catalanes, aragoneses, castellanos, vascos, gallegos, ..., primer rey de una España unificada tras la desaparición de Hispania el año $711^{9}$.

Ciertamente Carlos el Emperador será el primer monarca propiamente español en el sentido de primer rey del territorio español global; instalado en la perspectiva medieval que resulta adecuada, nuestro autor ya había dicho años antes en una exposición suya de conjunto:

El matrimonio [de Fernando e Isabel] no fue por tanto la culminación de un proceso medieval, sino el comienzo de una fase de unificación histórica, cuya suerte dependerá del juego de fuerzas existentes, de la voluntad de quienes en adelante integren el nuevo Estado [...].

${ }^{9}$ Martin, José Luis: "De Hispania a las Españas. De la unidad romano-visigoda a la unificación de los Reyes Católicos", capítulo del volumen colectivo La Corona en la historia de España, Madrid, Biblioteca Nueva, 2003, pp. 19-41: p. 41. Y se extiende también: “La invasión musulmana del año 711 pone fin a la precaria unidad de la Hispania visigoda, cuyos reyes [...] sólo en determinados momentos lograron que su autoridad fuera reconocida y respetada en toda la Península. [...]” (p. 25). 
En pocos años (1474-1516) Castilla ha logrado superar las divisiones internas y la guerra civil endémica que se arrastraba desde el siglo XIII y ha impuesto su hegemonia sobre los reinos peninsulares (a excepción de Portugal). Unidos castellanos, aragoneses y navarros bajo la dirección de Castilla controlarán en la época moderna gran parte de Europa y de América ${ }^{10}$.

Se da así un hecho histórico - la unificación peninsular-que coincide con otra ruptura en lo idiomático: varios datos de lo lingüístico a partir de hacia 1519 no nos remiten ya a lo medieval, sino a la lengua moderna clásica (tras 1713/1815, con las reformas ortográficas de la Real Academia, y las reformas, los textos doctrinales y la autoridad académica, puede hablarse ya de la lengua moderna contemporánea).

Hasta hacia 1519/1554 se prolonga pues la Edad Media lingüística castellana, pero asimismo es verdad que si queremos ser fieles con la realidad debemos tener presente que desde 1492 ha surgido la realidad americana del idioma.

(A propósito de lo que hemos apuntado acerca de una discontinuidad en la lengua patrimonial a partir del Setecientos cabe recordar que en un brillante artículo, Chantal Melis, Marcela Flores y Sergio Bogard han mostrado que ya en el Ochocientos se han producido cambios que "han alterado importantes estructuras de la lengua", por lo que "el siglo $x \mid x$ se constituye en el inicio de una tercera etapa en la historia del español " tras el período clásico ${ }^{11}$; ciertamente esas innovaciones en las estructuras gramaticales son reales, pero creemos que varios datos llevan a no pensar que el idioma clásico llega hasta principios del xix. La lengua siempre encierra cambios, y en este caso lo que habria que decir sólo es que en algunos aspectos gramaticales, el español actual arranca del XIX y se diferencia del del XVIII; nos parece excesivo datar una gran tercera etapa del idioma sólo con el Ochocientos).

En definitiva del romance castellano medieval (y no sólo del castellano) tenemos documentados rasgos desde poco antes del año 900, y los caracteres medievales de la fonética, del verso, de la prosa literaria, ..., se van disolviendo desde hacia los inicios del siglo xvi; los cambios gramaticales se vienen escalonando desde hacia la mitad del Trescientos, según ha postulado - a partir de algún hecho- la misma C. Company.

\section{CONSTITUCIÓN GEO-HISTÓRICA E IDIOMÁTICA DE LA ESPAÑA ACTUAL}

Hay un dato de la distribución territorial de la Península que ha concretado bien Miguel Ángel Ladero, medievalista de relieve que se ha fijado en los años -aproximadamente-1050/1300, a los que considera la matriz común de la que derivará la España posterior, incluida en ella la España actual.

10 Martin, José Luis: La Peninsula en la Edad Media, Barcelona, Teide, 1980², pp. 765-766.

11 El artículo está publicado en la NRFH, LI/1, 2003, pp. 1-56. 
La España que hoy conocemos y vivimos (explica) se hizo en aquellos dos siglos y medio, en su territorio, en sus regiones - sólo Granada y Canarias son algo más recientes-, en su forma geo-histórica. Ningún otro período de la historia española puede parangonarse a aquél en estos aspectos. [... Hay otros] —sociales, políticos, culturales - que hacen de la plena Edad Media el tiempo en el que nacieron o maduraron verdaderamente la inmensa mayor parte de los aspectos que componen la realidad histórica originaria de la España actual. Lo anterior es casi siempre pre-historia de España ${ }^{12}$

Nuestro autor desarrolla asimismo cómo en estas centurias de la plena Edad Media se consolidaron una sociedad y una cultura dentro del modelo europeo general, o sea, dentro del Occidente medieval; existia por igual "un concepto ya muy elaborado sobre la existencia histórico-cultural de España que permitiría en el futuro [...] imaginar y justificar proyectos de convergencia política» ${ }^{13}$.

Si trasladamos este dato del relieve de 1050/1300 a lo lingüístico, podría decirse que es asimismo en esas centurias cuando va llegando a su fin la época denominada de orígenes próximos de la lengua, y cuando ocurre la consolidación del castellano hasta hacerse en la segunda mitad del Doscientos un idioma para todos los usos; antes de lo que simboliza Alfonso X cabria hablar sin falta a la realidad de los hechos de una cierta pre-historia del castellano, que sólo era entonces lengua vernácula y de la literatura en verso, no un idioma generalizado en los usos, crecientemente estandarizado, etc. ${ }^{14}$.

Aplicando los conceptos de los sociolingüistas - hemos dicho en otras ocasiones-, cabe mantener que con el monarca castellano, con el rey Alfonso el Décimo, el idioma pasa entre nosotros de su situación de «vernáculo» a la de «estándar». Refiriéndose a este modo lingüístico del estándar, proponia Willian A. Stewart que "Sus normas codificadas - reforzadas en muchos casos por obras literarias - tienden a fomentar un grado relativamente alto de uniformidad en el uso, aun alli donde los usuarios de la lengua están separados geográfica o socialmente" ${ }^{15}$; el autor viene a señalar pues que el estándar se halla codificado en obras gramaticales y que posee una "serie» o tradición literaria, y en efecto estas condiciones dan lugar a que hablemos de lengua ( lengua histórica») y no ya de un hablar vernáculo.

12 Ladero Quesada, M. A.: Lecturas sobre la España historica, Madrid, Real Academia de la Historia, 1998, pp. 34-35; lo mismo lo mantiene asimismo en su denso libro La formación medieval de España, Madrid, Alianza, 2004, pp. 16-17.

13 Lecturas..., pp. 68-69, en las que también escribe: "Habia madurado una constitución política en Coronas y reinos, con diversas formas y repartos internos de poder en los que podemos distinguir dos modelos: el catalano-aragonés y el navarro, por una parte. el castellano-leonés, por otra, más abierto este último al desarrollo del Estado monárquico"

14 Desde luego lo ocurrido con el idioma patrimonial en el Doscientos no puede reducirse sólo al rey Alfonso; las complejidades de lo que sucede las ha argumentado con buen conocimiento de la documentación -en varios artículos suyos-Pedro Sánchez-Prieto Borja.

15 Cfr. Stewart, W. A.: "Un bosquejo de tipología lingüistica para describir el multilingüismo", incorporado a la Antología de estudios de etnolingüistica y sociolingüistica de Paul L. GARVIN y Yolanda Lastra, México, UNAM, 1974, pp. 224-233: p. 228. 
El servir de vehículo a una densa tradición literaria y el estar ordenada en textos gramaticales da su estatuto a la lengua, y la nivela y fija asi; hace mucho tiempo Menéndez Pidal sugirió también que entre otras cosas el manifestarse a través de una serie literaria y el acabar de imponerse de esta manera a otros vernáculos del mismo origen, dan a un código idiomático su carácter de lengua (histórica); con la ampliación alfonsí a la prosa escrita, con el uso prácticamente generalizado, el castellano casi sólo vernáculo se hace un código estándar.

El español actual arranca pues del castellano que va constituyéndose en las centurias de la plena Edad Media con un momento representativo en Alfonso $X$, al igual que territorial y regionalmente la Peninsula se ordena fundamentalmente en el mismo tiempo: del idioma común puede decirse algo análogo a lo que el prof. Ladero explica de la distribución del territorio asimismo patrimonial en varios artículos suyos ${ }^{16}$.

\section{SOBRE CORONIMIA}

El propio M. A. Ladero ha historiado, por ej., las raíces de lo que sería Castilla la Nueva, y en este caso nos ilustra así:

La plena individualización política de Toledo y su región se produjo al disgregarse el califato de Córdoba a comienzos del siglo XI [...]. Se formó entonces un reino taifa con capital en la ciudad, que [...] comprendia las tierras de la Meseta sur, desde los macizos de la Cordillera Ibérica, al este, hasta bien entrada la actual Extremadura, al oeste, desde el Sistema Central, al norte, hasta Sierra Morena, al sur. Por primera vez se perfiló, desde el punto de vista histórico-político, el área de lo que sería, en el futuro, Castilla la Nueva, o reino de Toledo ${ }^{1}$.

A su vez y desde la perspectiva idiomática tiene interés la designación Castilla la Nueva, y por eso recogemos ahora en abreviatura algunos de los datos que ya hemos manejado en ocasión anterior.

Hay que tener en cuenta lo tardío - el Quinientos- de esta denominación de Castilla la Nueva para el territorio toledano, que fue llamado en efecto en la documentación del siglo xı y sucesivos (Menéndez Pidal lo notó ya) Tras-Sierra, reino de Toledo, etc.

De nuestra parte podemos registrar cómo Francisco Delicado - quien se consideraba de Martos (Jaén) - manifiesta en 1534 que es "de Castilla la baxa", y

16. Sobre "la evolución lingüistica en la Baja Edad Media" vid. la parte corresporidiente de la colectiva Historia de la lengua española hecha por más de cuarenta autores: Barcelona, Ariel, 2004, parte que en opinión de algún colega experto y asimismo en la nuestra modesta, encierra varios de los capítulos más conseguidos de todo el volumen.

17 La formación..., p. 192. 
hace referencia a «los de Castilla la baxa que son de Toledo acá yuso»: denomina desde luego a «Toledo» en cuanto ciertamente Castilla la baxa ${ }^{18}$.

Fuente documental de relieve son las Relaciones histórico-geográfico-estadisticas de los pueblos de España hechas por iniciativa de Felipe II, según las denominan sus editores Carmelo Viñas y Ramón Paz. En ellas hemos encontrado cómo se dice del lugar de Arroba : "Cae en el reino de Toledo en Castilla", y del de Los Cadocos: "Cae en el reino de Castilla y montes de Toledo". De la villa del Castillo de Bayuela se dice que "cae y se cuenta por reino de Toledo por ser de puertos aca», y del lugar de Lucillos encontramos: "Este lugar esta en Castilla la Nueva, porque ansi lo hemos oido nombrar de los puertos aca" ${ }^{19}$; en fin del lugar de San Bartolomé se dice que «el dicho lugar esta en Castilla en el reino de Toledo 20 .

Según podemos comprobar Los Cadocos y San Bartolomé manifiestan que son de la Castilla toledana, y Lucillos de esa misma Castilla o "Castilla la Nueva»; Arroba y Castillo de Bayuela tienen conciencia de pertenecer al Reino de Toledo. El corónimo Castilla la Nueva se encuentra ya empleado hacia mediados de los años setenta del siglo xvi, aunque coexiste con otras denominaciones.

Testimonio algo posterior es el de Padre Juan de Mariana, quien en su Historia General de España "puesta en lenguaje castellano" habla de los montes cercanos a Soria, Segovia y Ávila y manifiesta entonces que «en particular Castilla, la mayor de las provincias de España, se divide por estos montes en Castilla la Nueva y la Vieja»; con mayor claridad añade todavia el jesuita que «el reino de Toledo es asimismo parte de Castilla, el cual hoy se llama Castilla la Nueva" ${ }^{21}$ : Mariana vemos que testimonia como estandarizada y consagrada ya por el uso la designación coronímica "Castilla la Nueva».

Al testimonio del Padre Juan de Mariana se suman en coincidencia el de Aldrete, que distingue en 1606 entre “Castilla la vieja» y «la Nueua» 22, y Covarrubias, quien en el artículo que escribe de la voz Castilla dice en el Tesoro...: "Una de las provincias principales de nuestra España. [...] Dividese en Castilla la Nueva y Castilla la Vieja”. Entre los Iustros finales del Quinientos o quizá antes y los primeros del Seiscientos se encuentra estandarizado ya el corónimo Castilla la Nueva.

18 Tenemos presente la Introducción a una reimpresión veneciana del Primaleón que transcribe en parte don Eugenio ASENSIO en su erudito artículo "Juan de Valdés contra Delicado. Fondo de una polémica". Studia Philologica. Homenaje otrecido a Dámaso Alonso, Madrid, Gredos, I, 1960, pp. 101-113: pp. 110-111

19 Relaciones... Reino de Toledo (Primera parte), Madrid, CSIC, 1951, pp. 96, 187, 276, y 514.

2. Relaciones... Reino de Toledo (Segunda parte), Madrid, CSIC, 1963, p. 367.

21 Obras del Padre Juan de Mariana, I, BAE, Madrid. Atlas, 1950, pp. 4 a y 5 b.

22 ALDRETE, Bernardo: Del origen, y principio de la lengva castellana ó romance que oi se usa en Espana, ed. facsimilar de Lidio Nieto, Madrid, CSIC, MCMLXXII, pp. 191-192. 


\section{SOBRE CRISTIANOS, MOROS Y JUDIOS}

En las dos obras que venimos citando del prof. Ladero se mantiene algo que él no es el primero ni el único en sostener, pero que avala con su autoridad y que bastantes veces hemos dicho ya que creemos responde a la realidad; se trata de que «no hubo convivencia ni fusión: los cristianos de la Península recibieron bajo diversas formas influencias de la cultura andalusí, pero las integraron sin perder por ello sus rasgos culturales propios y su condición de [...] miembros de otro ámbito cultural».

La España concebida por Américo Castro es una España un tanto idealizada; en cualquier aspecto de la realidad que se considere - mantiene Ladero, luego de muchos años de estudio del Medievo-, el hecho dominante «fue la pertenencia de los reinos de España al mundo religioso, político y cultural del Occidente medieval»: de esta manera la ordenación de la sociedad, los fundamentos económicos y las formas del poder resultan homologables con las del resto de Europa, aunque no se diese identidad absoluta ${ }^{23}$.

En la profesión filológica acostumbra a darse gran valor explicativo a las tesis de don Américo; no obstante los hechos reales fueron harto más diversos y complejos de como los enseñaba este autor, que seguramente anheló e idealizó una España tolerante en la que cupiesen también los heterodoxos, la minoría intelectual institucionista, o laica, o republicana, o todo a la vez, de la que él formaba parte desde años tempranos de su vida ${ }^{24}$.

${ }^{24}$ Sobre la voz y el concepto España vid. el recuperado artículo de J. Vicens que aparece en Els Marges, 12, 1978, pp.111-114. 